\title{
PRODUTOS FLORESTAIS NÃO MADEIREIROS: POTENCIALIDADES E DESAFIOS, UM ACASO DA COMUNIDADE SANTO EZEQUIEL MORENO - PA.
}

\author{
Apresentação: Relato de Experiência \\ Nagib José Carvalho de Lima Junior ${ }^{1}$; Darleny Cristina Serrão Penish²; Paulo Renato Souza de \\ Oliveira $^{3}$; Camila Cristina Soares Lobato'; Gracialda Costa Ferreira ${ }^{5}$.
}

\section{Introdução}

A extração dos produtos florestais não madeireiros (PFNMs) no Brasil é de grande importância social, econômica e ambiental. Apresenta-se como forma de exploração sustentável, pois, na maioria das vezes, não implica a remoção dos indivíduos das espécies. Há tempos, populações tradicionais, extrativistas e ribeirinhas, bem como agricultores familiares, utilizam estes produtos não madeireiros (frutos, fibras, resinas, plantas medicinais, utensílios, entre outros) como meio de subsistência e/ou fonte de renda (IPEA, 2016).

Entre vários PFNMs manejados pela comunidade, o açaí (Euterpe Oleracea Mart.), uma palmeira que faz parte da vegetação natural do ecossistema de várzea e terra firme, apresenta o maior potencial de demanda e oferta, apresentando uma importante fonte de alimentação e renda para esses ribeirinhos do estuário amazônico. Contudo, esses extrativistas enfrentam problemas em relação ao escoamento da produção do fruto que tem maior rentabilidade para eles, o objetivo desse relato é mostrar essas dificuldades e as possíveis mitigações para os mesmos.

\section{Relato de Experiência}

Este relato é fruto de uma vivência, onde um grupo de estudantes de engenharia florestal da Universidade Federal Rural da Amazônia, Belém, PA, passaram duas semanas na comunidade Santo Ezequiel Moreno, localizada no município de Portel - PA, a sul/sudoeste da Ilha de Marajó, a 278 quilômetros de Belém. O acesso principal até a ilha é por via fluvial e a viagem de barco dura aproximadamente 16 horas a partir da capital estadual e mais 2 horas de barco até a comunidade Santo Ezequiel Moreno (IBGE, 2000).

Durante a vivência foi possível conhecer um pouco da realidade desses ribeirinhos por meio (de um levantamento de dados realizado através) da aplicação de um questionário de campo. A comunidade é composta por 21 famílias, das entrevistadas 43\% sobrevive da agricultura e extrativismo, 38\% apenas do extrativismo e os demais apenas da agricultura. Através de parcerias da associação da comunidade juntamente com instituições como: Empresa de Assistência Técnica e Extensão Rural - EMATER, Secretaria Municipal de Meio Ambiente de Portel - SEMAS, Agência de Defesa Agropecuária do Estado do Pará - ADEPARA, Instituto Federal de Ciência e Tecnologia

${ }^{1}$ Engenharia Florestal, Universidade Federal Rural da Amazônia, juniornagib18@gmail.com

${ }^{2}$ Engenharia Florestal, Universidade Federal Rural da Amazônia, darlenypenisch@gmail.com

${ }^{3}$ Engenharia Florestal, Universidade Federal Rural da Amazônia, pr.oliveira0@gmail.com

${ }^{4}$ Engenharia Florestal, Universidade Federal Rural da Amazônia, milacristina2@gmail.com

${ }^{5}$ Docente, Universidade Federal Rural da Amazônia, gracialdaf@yahoo.com.br. 
- IFPA e a Universidade Federal Rural da Amazônia - UFRA foi possível promover cursos de capacitação para a exploração dos PFNMs para os comunitários.

Em relação ao aspecto organizacional, a comunidade está dividida em pelos menos cinco tipos de representações: sindicato, mutirão, associação, cooperativa, grupo religioso. $\mathrm{Na}$ comunidade, existe o Fundo Açaí, uma iniciativa autogerida pela própria comunidade, onde cada extrativista destina $\mathrm{R}$ \$2,00 de cada lata de açaí de vendida, “através desse fundo foi possível trazer grandes melhorias para a comunidade: Ampliação do centro comunitário, construção da passarela que liga as casas da comunidade, e também água potável”, afirma Nilson Silva, vice-presidente do Fundo Açaí.

Cerca de 70\% das famílias comercializam algum tipo de PFNMs, através do questionário foi possível evidenciar os principais problemas na venda do Açaí: atravessadores e preço, transporte e acessibilidade, demanda de mercado e produção, armazenamento e durabilidade e energia elétrica. Apesar de grande parte da comunidade esta ligada em algum grupo de representação, o grande gargalo deles ainda é o atravessador que compra por um preço abaixo do desejado pelos comunitários e revendem acima do preço de mercado.

\section{Considerações}

A comunidade Santo Ezequiel Moreno possui grandes potencialidades e está em um nível considerado de organização social, fator importante para a consolidação de políticas públicas na comunidade, porém é necessário maior incentivo dos órgãos competentes para que esta venha a superar os seus desafios e venham conquistar novos espaços e fortalecer a associação desses comunitários para que não fiquem submissos a esses atravessadores, fazendo com que os seus produtos tenham um preço justo e valorizando os trabalhos desses extrativistas.

\section{Referências}

IPEA - INSTITUTO DE PESQUISA ECONOMICA APLICADA. Cadeias de Comercialização de Produtos Florestais não Madeireiros na Região de Integração Rio Capim, Estado do Pará. Brasília, IPEA, 2016. Disponível em: http://www.ipea.gov.br/portal/index.php?option=com_content\&view=article\&id=27581. Acesso em 02/10/2017.

IBGE - INSTITUTO BRASILEIRO DE GEOGRAFIA ESTATISTICA. Censo Demográfico, 2010. Disponível em: < https://cidades.ibge.gov.br/painel/populacao.php?lang=_EN\&codmun=150580\&search=par\%E1\%7 Cportel>. Acessado em 28/10/2017. 